\title{
SEASONAL AND LONG TERM RAINFALL TRENDS IN CALABAR, NIGERIA
}

IGWE O. EWONA AND SUNDAY O. UDO

(Received 21, February 2008; Revision Accepted 15, January 2009)

\begin{abstract}
Rain fall trends all over the world with the attendant socio-economic effects have taken unprecedented dimensions in recent times. Trend studies of this atmospheric parameter will enable us examine the nature of variation and possible causative agents. Both seasonal and long term trends of rain fall in Calabar between 1985 and 2003 have been examined. Monthly and annual rainfall totals, number of rain days and extreme rain fall indices were determined as secondary data and used for the analyses. SPSS statistical package was used to deseasolnalise the data and determine its trend. Both raw data and deseasonalised data were used to examine long term trends and both show some level of increase in rainfall of about $1.9 \mathrm{~mm}$ and $300 \mathrm{~mm}$ respectively. The results also show that rainfall has highly pronounced season. The seasonality of all the parameters namely total rainfall, total extreme rainfall, total number of rain days and number of extreme rain days were all similar, with a slight break in the month of August. This break introduces a week or more of drought which is essential for crop production, drying and storage of agricultural products and their by- products .
\end{abstract}

KEYWORDS: Calabar, extreme rainfall, extreme intensity, SPSS, deseasonalised data, Trend

\section{INTRODUCTION}

The sudden increase in cases of flooding all over the world has been blamed on Climate change. Flooding is the immediate consequence of increased precipitation. This study therefore aims at examining the nature of rain fall in Calabar over a 19 -year period in order to capture any evidence of climatic change. In the tropics and monsoon areas of the world, the frequency and intensity of rainfall in a particular season results in seasonal floods (Okpiliya, et al., 2006). The study of rainfall distribution is also important in rain harvesting, agricultural production especially plant production. The seasonality of rainfall invariably affects crop and animal production. Storage of agricultural products, architectural designs, building and construction, field work and tourism, also depend on the seasonality of rainfall. Rainfall intensities have a clear bearing on flooding, soil fertility and mineral circulation in the soil. Rainfall intensities also reduce infiltration capacities or the drainage network (Ebisemiju, 1989). The phenomenon of intense rainfall increases surface runoff which results in gully erosion-one of the largest ecological problems of the world. Data records published between1989 and 1996 by the National meteorological services, (NIMET) show that of all the state capitals in Nigeria rainfall is highest in Calabar, (NIMET, 2006)

Haylock and Nicholls (2000) reports that researchers seem to be more comfortable with working on such parameters as total rainfall, extreme intensity, extreme frequency, extreme event and total rain days when dealing with rainfall data. Though the proportional contribution from extreme events to the total rain fall depends on the method used to calculate the index, an increase in the number of rain days often increases with total rainfall and extreme frequency (Haylock and Nicholls, 2000, Karl et al, 1995, Nicholls, 1995, Hennessy et al, 1999). Karl and Knight (1998), for instance, found increase in both the intensity and the frequency of extreme events over the USA using thresholds based on long term mean percentiles. Correlations with total rainfall for the number of rain days and the three extreme indices namely extreme intensity, extreme percentage and extreme frequency show highly significant correlations for rain days with extreme frequency and extreme intensity. The implication is that years with high rainfall receive rain on more days, with a higher average intensity in the highest events and a larger number of events above an extreme threshold.

Daily rainfall records for 1961 - 1990 were analyzed for three stations in Northern Nigeria and one in Southern Nigeria. The authors found consistent decrease in annual rainfall of $8 \mathrm{~mm}$ per year in all four stations. The majority of the reduction occurred in August or September. The authors attributed the reduction to the decrease of $6-25$ days in the number of rain days during the rainy season. There was no significant change in the average rainfall per rain day except in Southern Nigeria which shows a slight decrease (Hess et al, 1995). Analyses of global circulation models suggest an increase in heavy rainfall and a decrease in light rainfall (Gordon et al, 1992, Haylock and Nicholls, 2000).

\subsection{Data source and analyses}

The basic daily data on rainfall, used for the study where extracted from the meteorological records 
of the Margaret Ekpo International airport in Calabar, from 1985-1994 - a period of ten years and from the National Meteorological services data bank in Lagos, from 1993-2003 - a period of 11 years. Present study is based on continuous set of data collected between 1985 and 2003 from where monthly and annual total values were computed.

The final set consists of a continuous unbroken mean monthly data set from 1985-2003 where the months are numbered chronologically from January 1985 as month 1 up to December 2003 as month 228. Such continuity is necessary in time series analysis and where trend studies are involved. Daily measured data that were missing were not estimated by interpolation or other means and were not used in the analyses. This followed the method applied by Dugas and Heuer (1985). A time series analysis was carried out on the data collected using SPSS statistical package.

\subsection{RESULTS}

\subsection{Seasonal variations}

We used the moving average to ratio technique to decompose the series and had the seasonal index shown in Table 1. The seasonal index is the total fractional average monthly contribution during the period. The technique provides for the monthly fractional contribution of rainfall in twelve equal weightings- each month being assigned an equal weighting of unity. The actual average fractional rainfall in a month during the period therefore gives the seasonal index for that month. Inspecting the seasonal index, we note that rainfall has a pronounced season which starts from April and peaked in July. The rainfall season which spans between April and October coincides with the duration of south west trade winds which blows across Africa and the Indian sub continent (Microsoft Encarta, 2006). Months of December and January are almost without rain while February and March have limited rain. This is shown clearly in Figure 2.

Table 1: Seasonal index of monthly daily total rainfall.

\begin{tabular}{|l|l|l|l|l|l|}
\hline JAN & FEB & MARCH & APRIL & MAY & JUNE \\
\hline 0.088025 & 0.117689 & 0.751728 & 1.074664 & 1.109222 & 1.656606 \\
\hline JULY & AUG & SEPT & OCT & NOV & DEC \\
\hline 1.87694 & 1.650555 & 1.638995 & 1.318859 & 0.618184 & 0.098534 \\
\hline
\end{tabular}

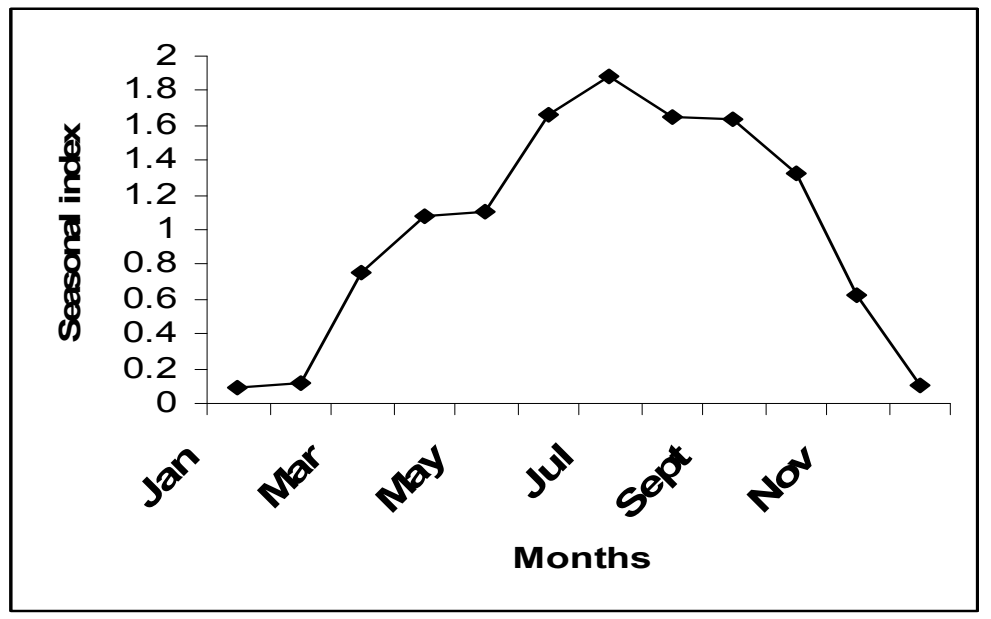

Fig. 1: Plot of seasonal index.

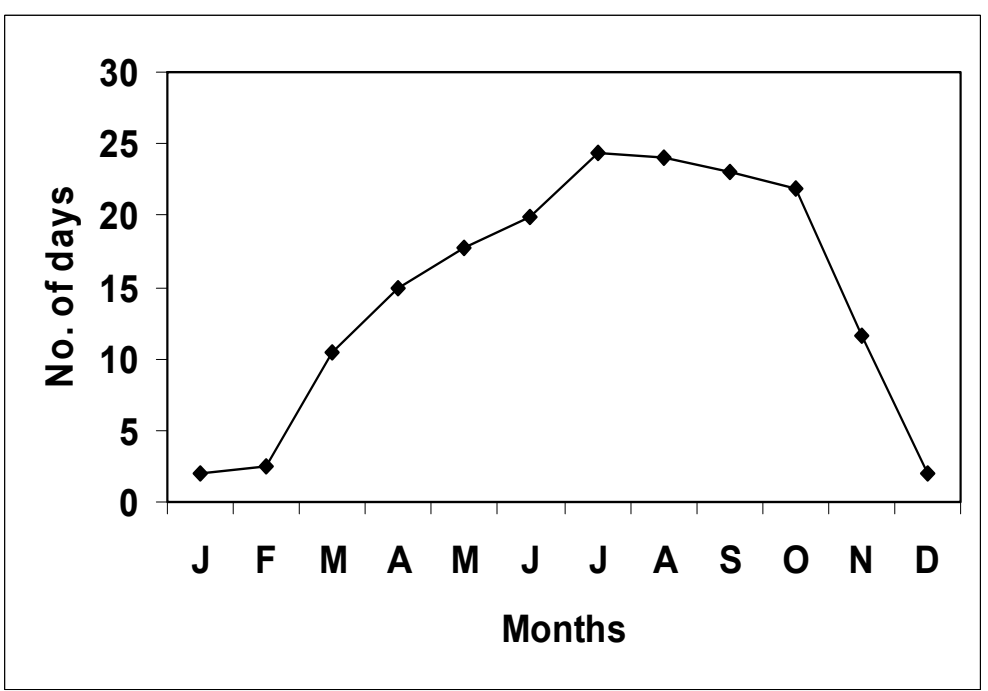

Fig. 2 Seasonal variation of monthly total number of rain days. 


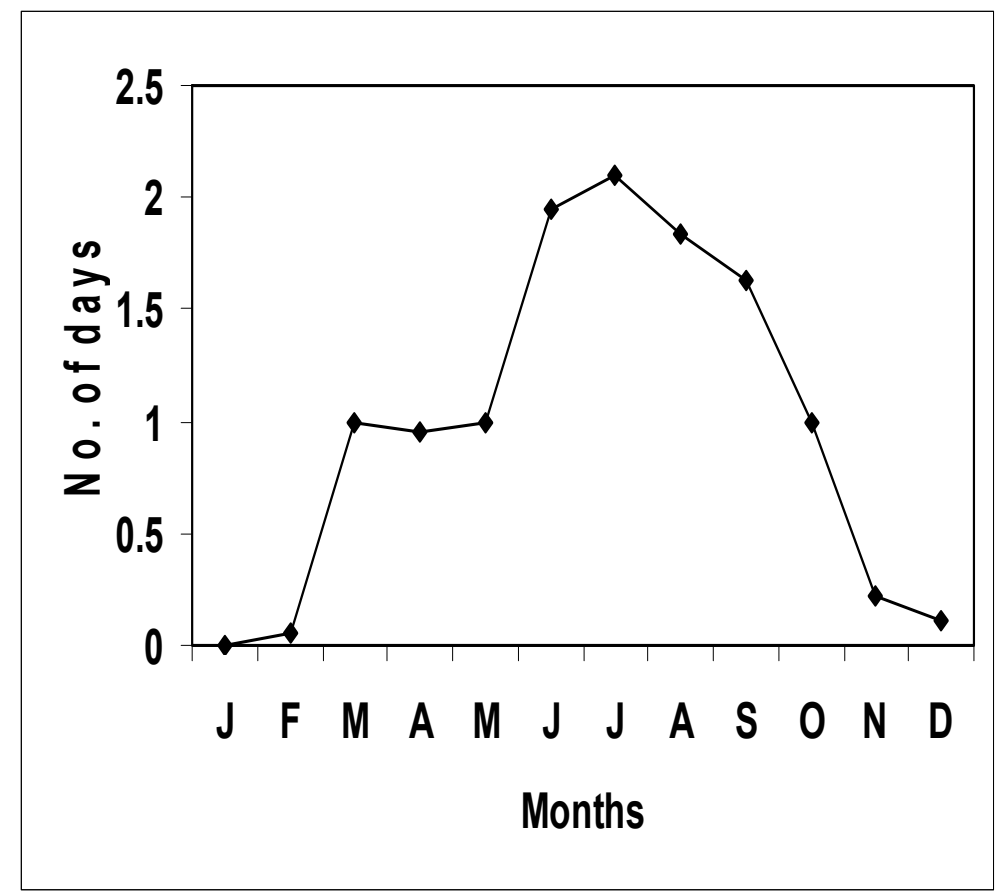

Fig. 3 Seasonal variation of monthly total number of days of intense rainfall.

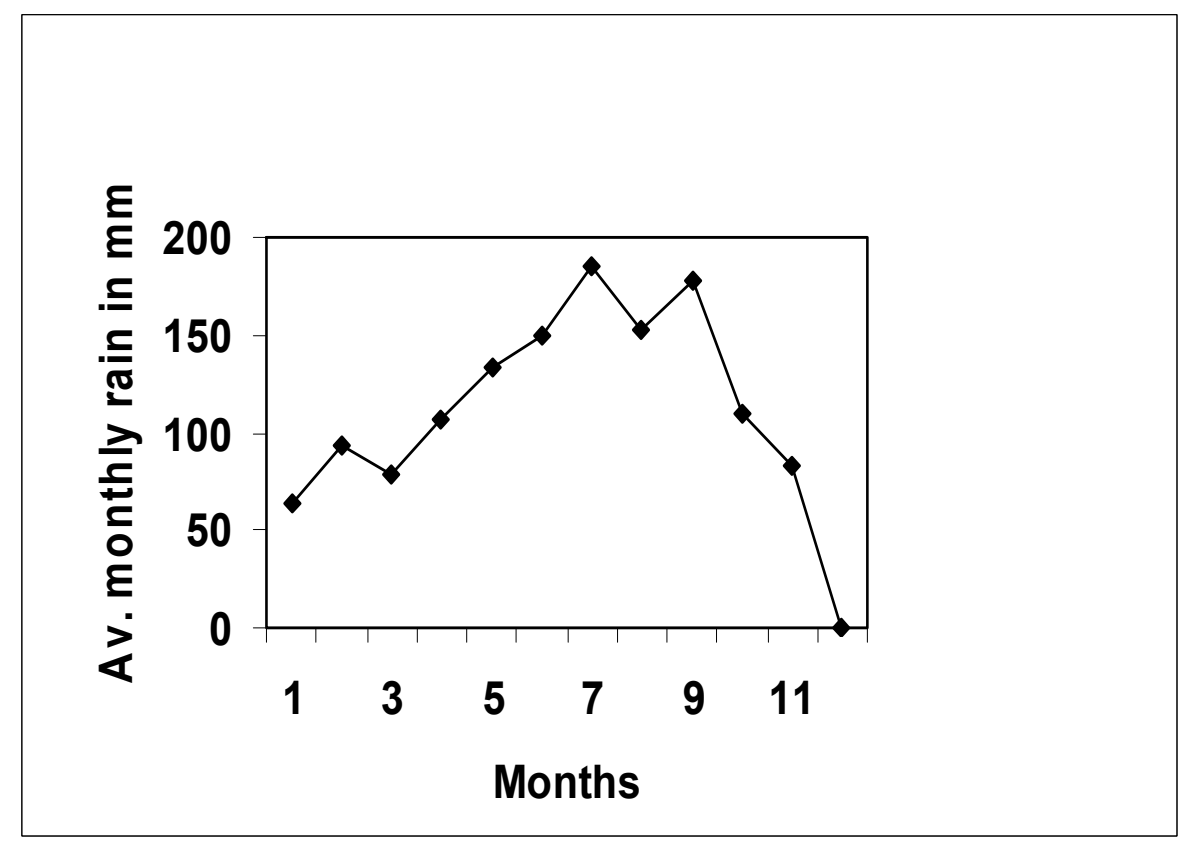

Fig. 4 Seasonal variation of average monthly total rainfall.

The results of Figure 2-4 clearly show the presence of strong seasonal tendency of rainfall in the area. Each of the factors used seem to peak in July with lowest valued found around December to February. We notice a slight decrease in the month of August even in the total rainfall as shown in Figure 4 . It is generally witnessed by a period of almost one week of little or no rain. This is normally referred to as "August break". The near absence of this "break" in some parameters shows that this phenomenon is weak here compared to other cities lying northwards.

\subsection{Long term variations}

Long term variations have been analyzed using such indices as total annual rainfall, number of rain days in the year, total extreme annual rainfall, number of days of extreme rainfall in the year. This is shown in Figure 58. 


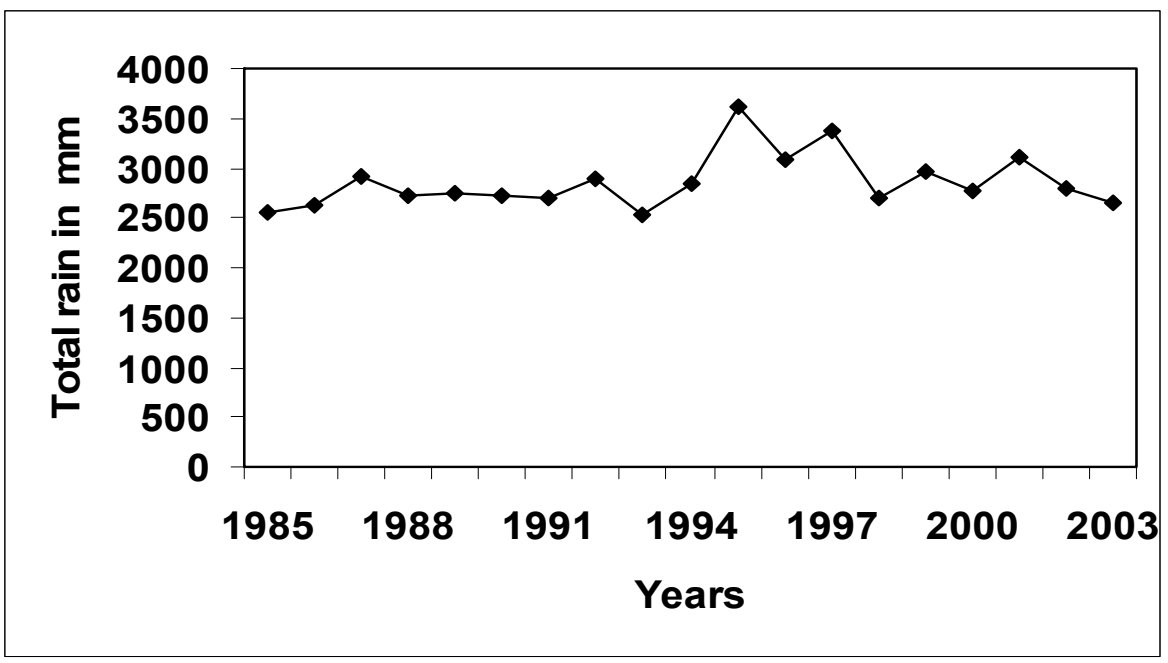

Fig.5 Trend graph of monthly daily total rainfall against months.

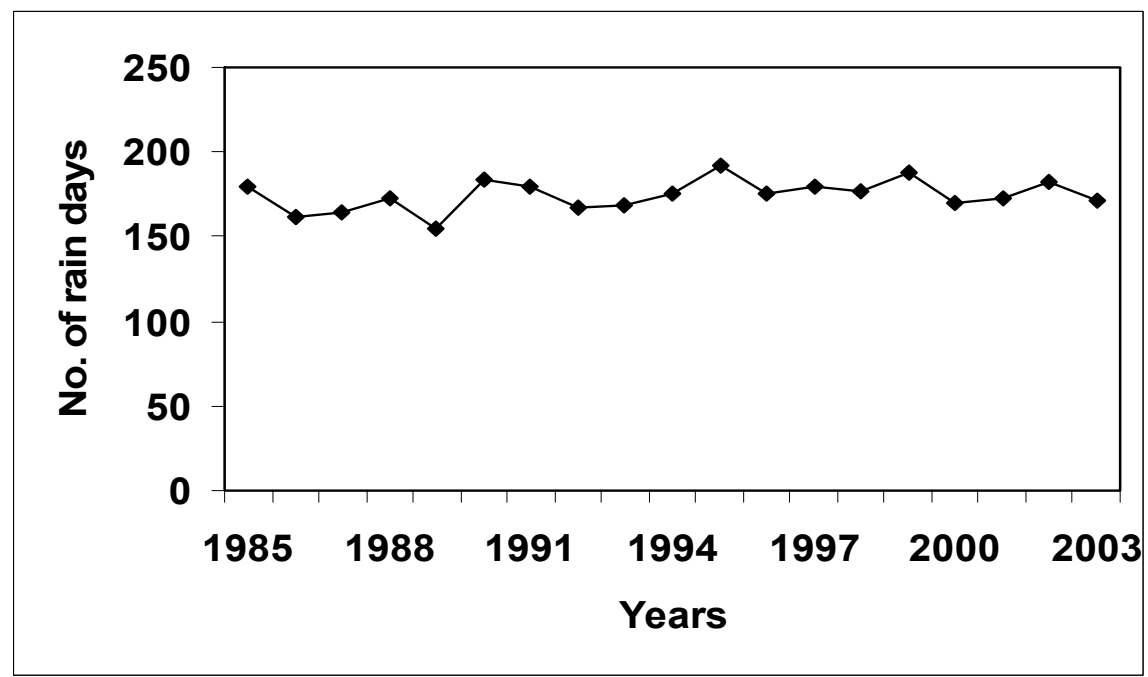

Fig.6 Trend graph of monthly number of rain days against months.

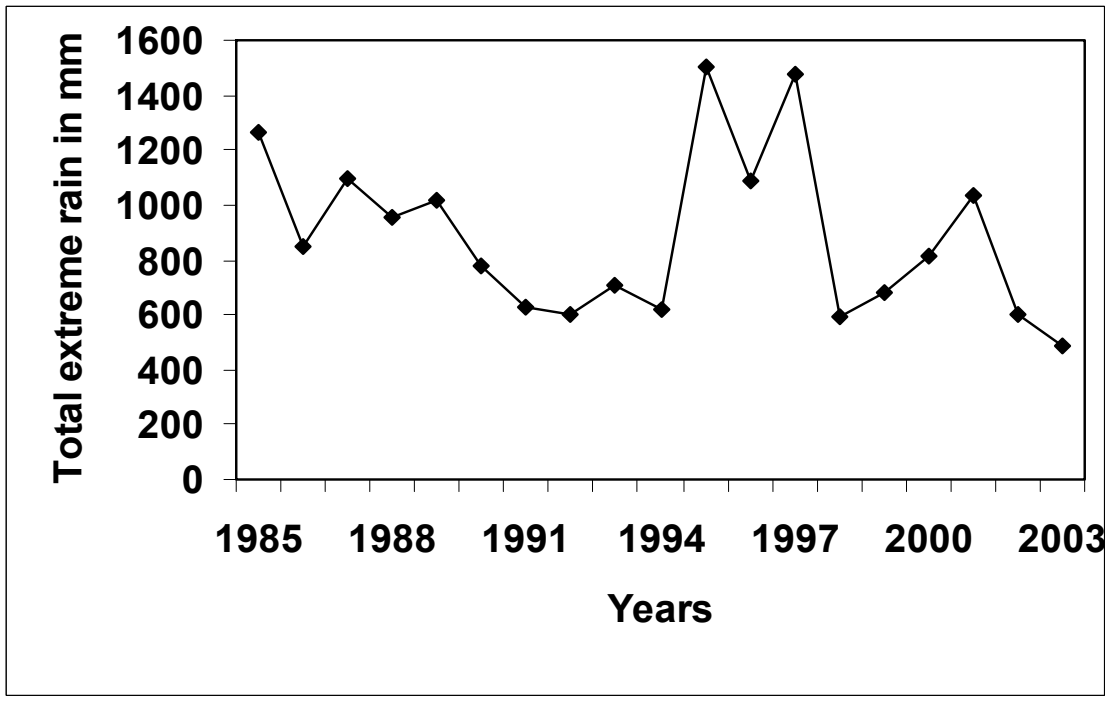

Fig.7 Trend graph of annual total monthly extreme rainfall against months. 


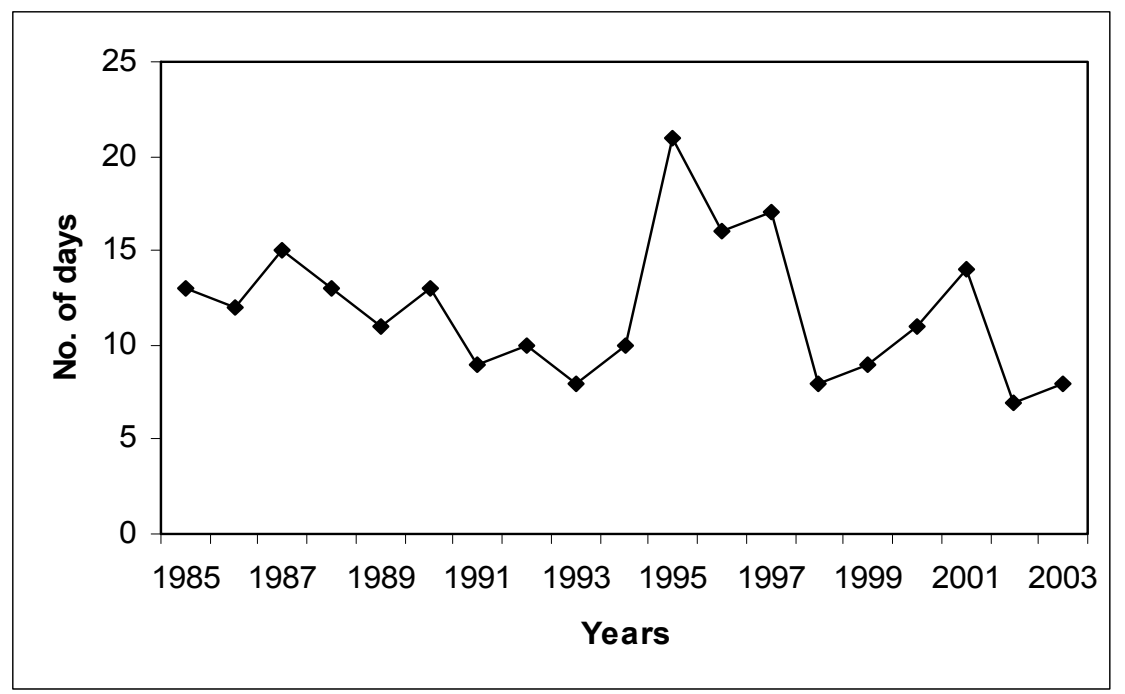

Fig. 8 Trend graph of annual total number of extreme rain days.

To remove the effect of seasonality from the data, we first calculate the seasonal index and then use it to deseasonalise or remove seasonal effects from the data. This is important as seasonal effects generally obscure long term trends on time series data, (Ewona and Udo, 2008; Priestly, 2005; McDonell, and Newell, 1962). Plotting the correlelogram of the data using SPSS statistical package, we note that the deseasonalised data is stationary only after a first difference transformation. The stationary plot is shown in Table 2, from where we identify a probable model of the rainfall data as autoregressive model of order four i.e. $\mathrm{AR}(4)$ as shown in Table 2b. Hence, the trend of the deseasonalise data follows the AR(4) model after a first difference transformation. The parameters of this model were generated using SPSS statistical package and are shown in Table 3. A plot of this model using the same package is shown in Figure 10. From the trend parameters in Table 3, we can write the general form of the trend equation as

$R_{x}=-0.77818187 R(x-1)-0.51748521 R(x-2)-$ $0.39325556 R(x-3)-0.21626646 R(x-4)+e_{x}$

Where $R_{x}$ is a data point at $x$ and $e_{x}$ is the error component.

Table 2 : (a) autocorrelation (b) partial autocorrelation

Auto- Stand.

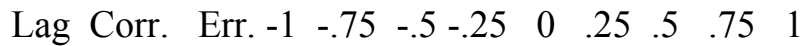

$\begin{array}{lll}1 & -.523 \quad .066\end{array}$

$\begin{array}{lrrr}2 & .080 & .066\end{array}$

$\begin{array}{llll}3 & -.075 & .066\end{array}$

$\begin{array}{llll}4 & .007 & .065\end{array}$

$\begin{array}{llll}5 & .016 & .065\end{array}$

$\begin{array}{lll}6 & -.001 & .065\end{array}$

$\begin{array}{llll}7 & .033 & .065\end{array}$

$\begin{array}{lll}8 & -.022 & .065\end{array}$

$\begin{array}{lll}9 & -.031 & .065\end{array}$

$\begin{array}{lll}10 & -.038 & .065\end{array}$

$\begin{array}{lll}11 & .126 & .064\end{array}$

$\begin{array}{llll}12 & -.040 & .064\end{array}$

$\begin{array}{lll}13 & -.051 & .064\end{array}$

$\begin{array}{llll}14 & -.048 \quad .064\end{array}$

Pr-Aut- Stand.

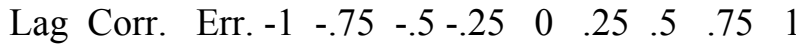
+----+-----+----+-----+----+-----+----+----+.

$\begin{array}{lll}15 & .094 \quad .064\end{array}$

$\begin{array}{lll}16 & -.039 & .064\end{array}$

I**. $* \mathrm{I}$.

(a) Autocorrelations: Deseasonalise Rainfall Data 
Transformations: difference (1)

\begin{tabular}{|c|c|c|}
\hline $1-.523$ & .066 & $* * * * * * * * * \mathrm{I}$ \\
\hline $2-.266$ & .066 & $* * . * * \mathrm{I}$ \\
\hline $3-.239$ & .066 & $* * . * * \mathrm{I}$ \\
\hline $4-.218$ & .066 & $* * * \mathrm{I}$ \\
\hline $5-.164$ & .066 & $* * * \mathrm{I}$ \\
\hline $6-.132$ & .066 & $* * * \mathrm{I}$ \\
\hline $7 \quad-.057$ & .066 & *I \\
\hline $8-.037$ & .066 & *I \\
\hline $9-.080$ & .066 & $* * I$ \\
\hline $\begin{array}{ll}10 & -.167\end{array}$ & .066 & $* * * I$ \\
\hline $11-.006$ & .066 & $*$ \\
\hline 12.044 & .066 & $\mathrm{I}^{*}$ \\
\hline $13-.047$ & .066 & $* \mathrm{I}$ \\
\hline $14-.171$ & .066 & $* * * \mathrm{I}$ \\
\hline $15-.073$ & .066 & $*$ I \\
\hline $16-.071$ & .066 & $*^{*} \mathrm{I}$ \\
\hline
\end{tabular}

(b) Partial Autocorrelations: Deseasonalise Rainfall Data Transformations: difference (1)

Table 3: Variables in the model.

\begin{tabular}{|l|l|l|l|l|}
\hline & \multicolumn{1}{|c|}{ B } & \multicolumn{1}{|c|}{ SEB } & \multicolumn{1}{|c|}{ T-Ratio } & Approx Prob \\
\hline $\mathrm{AR}_{1}$ & -0.77818187 & 0.06485096 & -11.999543 & 0.0000000 \\
\hline $\mathrm{AR}_{2}$ & -0.51748521 & 0.07876901 & -6.569655 & 0.0000000 \\
\hline $\mathrm{AR}_{3}$ & -0.39325556 & 0.07874974 & -4.993738 & 0.00000118 \\
\hline $\mathrm{AR}_{4}$ & -0.21626646 & 0.06494949 & -3.329764 & 0.00101494 \\
\hline
\end{tabular}

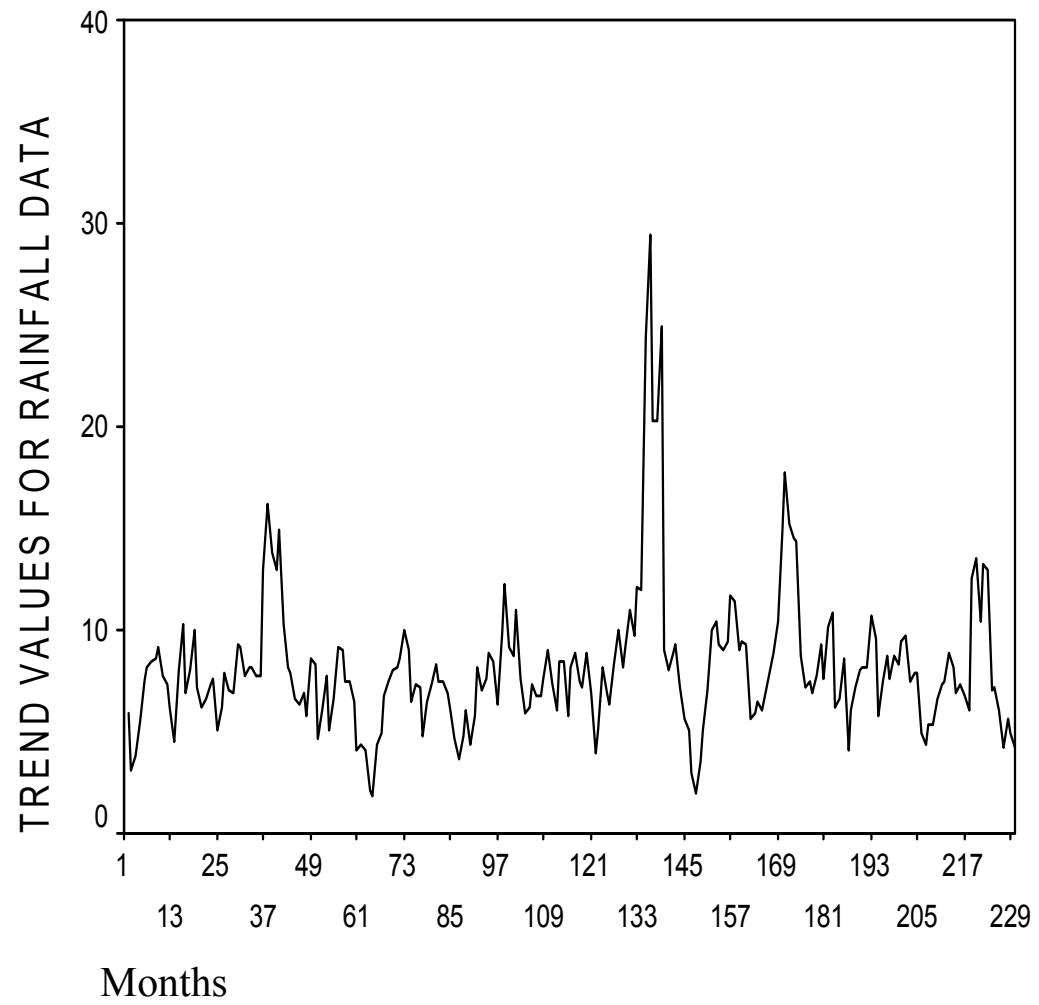

Fig. 9: Trend graph of deseasonalised monthly daily total rainfall against months.

A close study of Figures 5 and 9 reveals the effect of seasonality on time series data. The deseasonalised monthly total rainfall shows an increased of about $1.9 \mathrm{~mm}$ whereas the raw data gave an increased of about $300 \mathrm{~mm}$. Again, a close study of
Figure 9 shows that only the months $133-140$ which lie in the years 1995 and 1996 were exceptionally wet whereas Figures 5,7and 8 shows that 1997 was also as wet. The difference between the two trend analyses 
shows that seasonal variations are much stronger than trend variations in this part of the world.

The data for 1995-1997 seem to constitute a major departure from common trends in the area for all parameters used in these analyses. No suitable explanation has been found for this phenomenon. We suspect this to be an aftermaths of the Pinatubo volcanic eruption in the Philippines in 1991 and 1992 which poured out large volumes of aerosol particles into the upper atmosphere. These particles may have drifted into this area through air currents. The resultant effect being the lowering of the earth's temperature and increased precipitation in most parts of the world, (Ulack, 2007).

If we consider the data for the years 1995-1997 as outliers and remove them from the analysis we notice a slightly increasing trend for annual total rainfall and the corresponding total number of rain days. However, all other parameters show a consistent decreasing trend as can be seen for total extreme rainfall in Figure 7 and the number of days of intense rainfall in Figure 8.

We observe from Figures 7 and 8 that even though the total number of rain days in the year have remain relatively constant or have increased only slightly, the number of extreme events seem to show a downward trend. This seems to contradict the findings of (Gordon et al, 1992, Haylock and Nicholls, 2000) which suggest an increase in heavy rainfall and a decrease in light rainfall globally. The work of Hess et al (1995) in southern Nigeria, seem to point to our findings when it observes only a slight decrease in rainfall as against large reduction of rainfall in other parts of Nigeria. The two parameters used- namely total extreme rainfall and number of days of extreme rainfall, strongly suggest the presence of a decreasing trend in heavy rainfall and surprisingly an increase in total rainfall inferring the resurgence of light rainfall.

\section{CONCLUSION}

The results of this work show a slight departure from predicted global trends. Analyses of global circulation models suggest an increase in heavy rainfall and a decrease in light rainfall. But we find rather an increase in light rainfall against heavy rainfall. Rainfall in Calabar is highly seasonal with a short break in the month of August. All the parameters used in the study indicate the same trend in seasonality. An evidence of the weight of seasonality is found in the difference between the long term trends of the deseasonalised and primary data. While the former shows and increase of only $1.9 \mathrm{~mm}$ the later shows a whopping increase of $300 \mathrm{~mm}$ over the period under review. We also found out that while the frequency of rainfall is increasing, the frequency of heavy rainfall is decreasing suggesting that there is increase in light rainfall in the area. The seasonality of Calabar rain which starts from April and ends in October coincides with the direction of Indian Monsoon winds which brings moisture from the Atlantic Ocean. The months of December to February have scanty and in some years no rain.

\section{REFERENCES}

Dougas, A. W. and Heuer, M. L., 1985. Relation between measured and satellite-estimated solar irradiance in Texas. Journal of Climate and Applied Meteorology, 24: 751-757

Ebisemiju, F., 1989. The response of head water stream channels to urbanization in the humid tropics: Hydrological processes, 3: 237-253

Ewona, I. O. and Udo S. O., 2008. Characteristic pattern of rainfall in Calabar, Nigeria - a tropical coastal location. Nig. J. of Phy 20(1):84

Gorden, H. B., Whetton, P. H., Pittock, A. B., Fowler, A. M. and Haylock, M. R., 1992. simulated changes in daily rainfall intensity due to the enhanced green house effect: implication of extreme rainfall events. Climate Dynamics 8: 83-102

Haylock, M. and Nicholls, N., 2000. High quality data set for Australia 1910-1998. Royal Meteorological Society, 8, 67

Hennessy, K. J., Suppiah, R. and Range, C. M., 1999. Australian rainfall change 1910-1995. Australian Meteorological Magazine, 48: $1-13$

Hess, T.M., Stephen, W. and Mayan, U. M., 1995. Rainfall trends in the north east arid zone of Nigeria 1961-1990. Agriculture and Forest Meteorology, 74(1-2): 87-89

Karl, T. R. and Knight, R. W., 1998. Secular trends of precipitation amount, frequency, and intensity in the United States. Bulletin of the American Meteorological Society, 79: 231-141

Karl, T. R., Derr, V. R., Easterling, D. R., Folland, C. K., Hofmann, D. J., Levitus, S., Nicholls, N., Parker, D.E., and Wittee, G. W., 1995. Critical issues for long term climate monitoring. Climate Change, 31: 185221.

McDonell, J. E., and Newell, J. E., 1962. Time step variations of winds heights and temperatures in the national meteorological centre. Primitive equation forecasts - A report. National Meteorological Centre Suitland.

Microsoft Encarta, 2006 [CD]. Trade winds, Redmond, WA. Microsoft corporation, 2005

Nicholls, N., 1995. Long term climate monitoring and extreme events. Climate Change, 31: 231-245

Nigerian Meteorological agency, NIMET, 2006. Climate: Rainfall in Nigeria. 
Okpiliya, F., Ekpoh, I. J., Afangideh, A. I. and Achi, A., 2006. Climate and human environment, Calabar, Tabson Resources.

Priestly, M. B. (ed.), 2005. Mathematics interdisciplinary applications. Time series analysis. Journal of Royal Meteorological Society, 87, 1-12

Ulack, Richard, 2007. "Mount Pinatubo." Microsoft@ Student 2008 [DVD]. Redmond, WA: Microsoft Corporation, 2007. 